\title{
Prevalence and Physical Distribution of SRY in the Gonads of a Woman with Turner Syndrome: Phenotypic Presentation, Tubal Formation, and Malignancy Risk
}

\author{
Tamar G. Baera Christopher E. Freeman ${ }^{\mathrm{b}}$ Claudia Cujar ${ }^{\mathrm{b}}$ Mahesh Mansukhani ${ }^{\mathrm{b}}$ \\ Bahadur Singh $^{b}$ Xiaowei Chen ${ }^{b}$ Rosanna Abellar ${ }^{b}$ Sharon E. Oberfield ${ }^{a}$ Brynn Levy $^{b}$ \\ ${ }^{a}$ Division of Pediatric Endocrinology, Diabetes and Metabolism, Columbia University Medical Center, New York, NY, \\ USA; ${ }^{b}$ Department of Pathology and Cell Biology, Columbia University Medical Center, New York, NY, USA
}

\section{Established Facts}

- Although monosomy $\mathrm{X}$ is the most common karyotype in Turner syndrome, $\mathrm{Y}$ chromosome material has been reported in about $10 \%$ of patients.

- The presence of Y chromosome material confers a risk of gonadoblastoma.

- Gonadoblastoma cells contain a high prevalence of Y chromosome material.

\section{Novel Insights}

- FISH and/or microarray-based studies should be considered for any patient with a structurally abnormal X chromosome, despite absence of virilization.

- Y prevalence may differ significantly in peripheral blood and gonadal tissue.

- The gonosome complement that makes up the majority of cells in gonadal tissue determines sexual phenotypic presentation.

- When Y chromosome material is present in the gonadal tissue of a woman with Turner syndrome, it is likely to localize exclusively in tubal structures in the gonad and be absent from any ovarian stroma that is present.

- Tubal structures may be present in the gonad despite a relatively low prevalence of Y chromosome material within the tissue itself.

\section{Keywords}

Turner syndrome · Gonadoblastoma · Y chromosome .

Gonosome Prevalence $\cdot$ Tubal structures

\section{Abstract \\ Although monosomy $\mathrm{X}$ is the most common karyotype in patients with Turner syndrome, the presence of $Y$ chromo- some material has been observed in about $10 \%$ of patients.}

Y chromosome material in patients with Turner syndrome poses an increased risk of gonadoblastoma and malignant transformation. We report a woman with a diagnosis of Turner syndrome at 12 years of age, without signs of virilization, and karyotype reported as $46, \mathrm{X}, \operatorname{del}(\mathrm{X})(\mathrm{q} 13)$. At 26 years, cytogenetic studies indicated the patient to be mosaic for monosomy $X$ and a cell line that contained a duplicated $\mathrm{Yq}$ chromosome. Bilateral gonadectomy was performed and revealed streak gonads, without evidence

\section{KARGER}

(c) 2017 S. Karger AG, Basel

E-Mail karger@karger.com

www.karger.com/hrp
Brynn Levy, MSc (Med), PhD, FACMG

Department of Pathology and Cell Biology, College of Physicians and Surgeons Columbia University Medical Center

3959 Broadway, CHC-Room 406b, New York, NY 10032 (USA)

E-Mailbl2185@cumc.columbia.edu 
of gonadoblastoma. Histological analysis showed ovarian stromal cells with few primordial tubal structures. FISH performed on streak gonadal tissue showed a heterogeneous distribution of SRY, with exclusive localization to the primordial tubal structures. DNA extraction from the gonadal tissue showed a $6.5 \%$ prevalence of SRY by microarray analysis, contrasting the $86 \%$ prevalence in the peripheral blood sample. This indicates that the overall gonadal sex appears to be determined by the majority gonosome complement in gonadal tissue in cases of sex chromosome mosaicism. This case also raises questions regarding malignancy risk associated with Y prevalence and tubal structures in gonadal tissue.

(c) 2017 S. Karger AG, Basel

\section{Background}

Turner syndrome is a common chromosome abnormality occurring in approximately 1:2,000 live female births [1]. The clinical features are highly variable and can be confirmed by chromosome analysis, which usually demonstrates complete or mosaic monosomy of the $\mathrm{X}$ chromosome. Although haploinsufficiency due to monosomy $\mathrm{X}$ is the most common karyotype found in Turner syndrome (50-60\%), other structural abnormalities in the $\mathrm{X}$ chromosome, such as ring chromosomes, isochromosomes of the long arm, and deletion of the short arm, have been reported [2,3]. Additionally, there have been reports of a Y cell line in about $10 \%$ of patients [4], as well as complex karyotypes with derivative $\mathrm{X}$ chromosome material [2].

The presence of Y chromosome material in patients with Turner syndrome is of integral importance as it increases the risk of developing gonadoblastoma, with an estimated risk of 7-10\% [5]. However, Y chromosome material is not always evident by standard karyotype analysis, and may require further study using newer cytogenomic techniques such as FISH and chromosomal microarray. Testing for $\mathrm{Y}$ chromosome material is suggested for patients who have signs of virilization, or if a marker chromosome is found on karyotype [6]. Here we report the case of a young woman with Turner syndrome. Detailed genetic analysis demonstrated mosaicism, with the majority of cells showing a duplicated Yq chromosome and the minority of cells showing monosomy X. Y chromosome material was also found in the gonads, exclusively localized to primitive tubal cells, although there were no signs of phenotypic virilization.

\section{Case Presentation}

The patient is a 26-year-old woman of Ashkenazi descent diagnosed clinically with Turner syndrome at age 12 . She was born full term with no complications to a G1P0 mother. She had never been hospitalized and had no medical issues at the time of presentation.

Karyotype analysis was performed at age 12 by a commercial laboratory and was reported as $46, \mathrm{X}, \operatorname{del}(\mathrm{X})(\mathrm{q} 13)$. A pelvic ultrasound was performed showing small ovaries and an uterus. She was also found to have aortic insufficiency and a bicuspid valve. She received treatment with growth hormone starting at age 12 until age 16, and underwent induction of puberty with oral estrogen supplementation at age 18 .

At age 26, physical examination showed a height of $155.4 \mathrm{~cm}$ and weight of $120 \mathrm{~kg}$. She had a normal chest shape, with Tanner $\mathrm{V}$ breasts and pubic hair. No evidence of clitoral enlargement or posterior labial adhesions was noted. Vaginal mucosa was estrogenized. Her extremities were notable for scooped nails, short broad thumb, and short 4 th and 5 th toes. She was referred to a reproductive endocrinology program for fertility workup and hormone replacement therapy. At that time, cytogenetic testing was repeated and included karyotype and FISH analysis. Cytogenetic analysis revealed an abnormal mosaic karyotype with approximately $12 \%$ of cells showing monosomy X $(45, \mathrm{X})$ and the majority of cells ( $88 \%$ ) showing a male genetic constitution with the Y chromosome containing a duplication of the entire euchromatic region of the long arm (46,X,dup(Y)(q.11.21q11.23) (Fig. 1). The level of mosaicism was estimated from both G-banded and FISH studies which included a total of 250 cells analyzed.

Chromosomal SNP microarray analysis was also performed with 2,696,550 probe targets and revealed $\operatorname{arr}[\mathrm{GRCh} 37](\mathrm{X}) \mathrm{x} 1, \mathrm{Yp}$ $11.31 \mathrm{p} 11.2(2,650,141-10,073,965) \times 1[0.86], Y q 11.21 \mathrm{q} 11.23$ $(13,800,734-28,799,937) \times 2[0.86]$ (Fig. 2a). This was interpreted together with the karyotype results as an estimated 14\% mosaic loss of the Y chromosome, with Y chromosome material present in $86 \%$ of the cells, with a duplication of the entire long arm euchromatic region from positions $13,800,734$ to $28,799,937$. This genetic constitution is equivalent to the $45, \mathrm{X} / 46, \mathrm{X}, \operatorname{dup}(\mathrm{Y})$ (q11.21q11.23) karyotype reported by standard G-band analysis.

Pelvic MRI showed a small uterus, and the ovaries could not be definitively identified. Due to the risk for gonadoblastoma, the patient underwent bilateral gonadectomy. Gross pathology showed right and left fallopian tubes with streak gonads. Dissection revealed ovarian stromal cells with conspicuous nuclei and scanty cytoplasm with few primordial tubal structures and calcification (Fig. 3). No evidence of gonadoblastoma was seen.

FISH using probes specific for the centromere of the X chromosome and the SRY region of the Y chromosome was performed on streak gonads and showed a heterogeneous distribution of SRY, localized exclusively to the areas with tubular remnants. SRY was absent in all ovarian stromal cells which showed the presence of only one X chromosome (Fig. 4). Chromosomal microarray analysis performed on DNA extracted from gonadal tissue paraffin sections showed approximately $6.5 \%$ prevalence of the $\mathrm{Y}$ chromosome material (Fig. 2b). The 46,X,dup(Y)(q11.21q11.23) cells thus appeared to be contained exclusively within the tubular tissue while the $45, \mathrm{X}$ cells were isolated to the stromal tissue. 


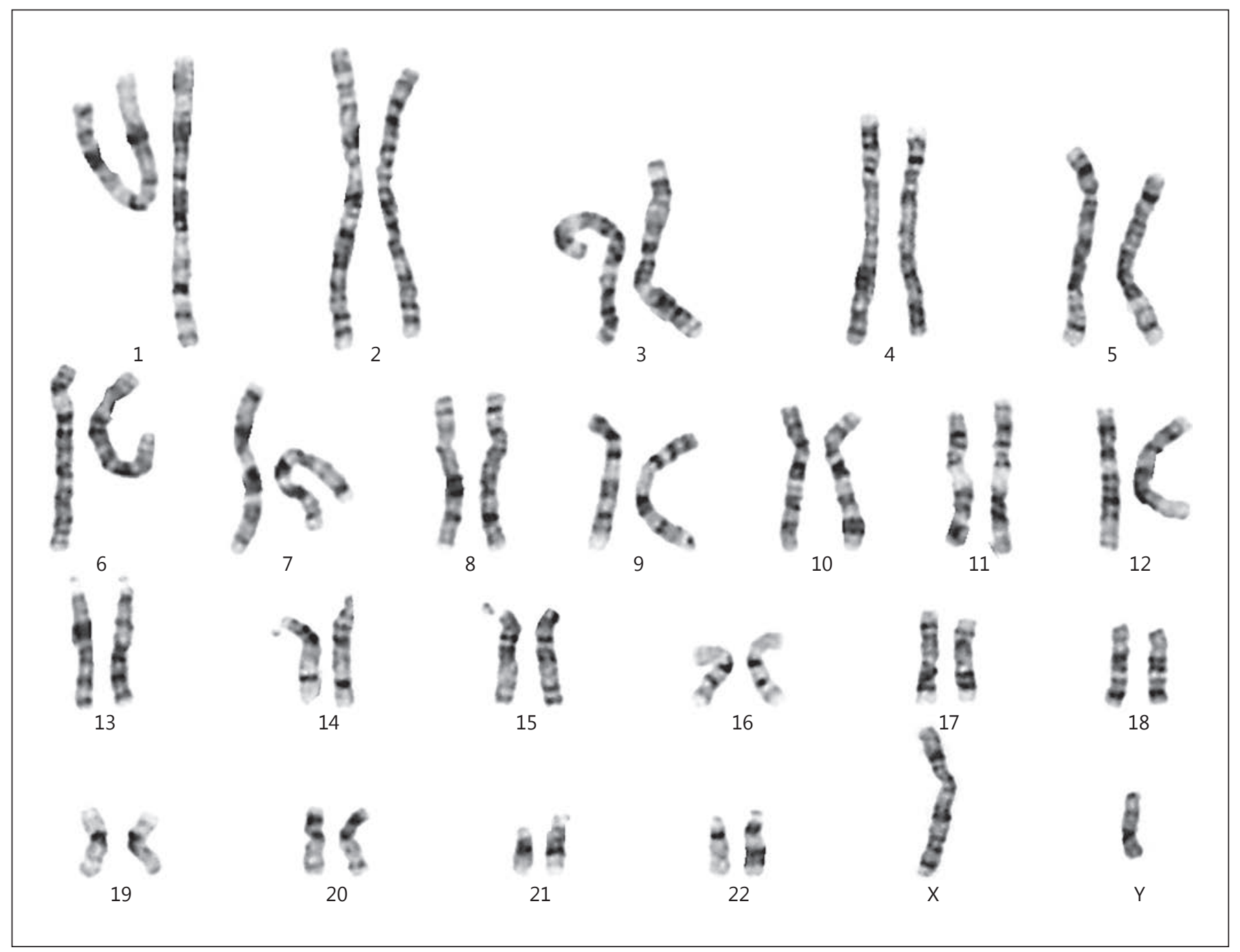

Fig. 1. G-banded karyotype showing 46,X,dup(Y)(q11.21q11.23).

\section{Discussion}

Multiple studies have shown the presence of previously undetected Y chromosome material in patients with Turner syndromes $[4,10-12]$. One study in Denmark found that 14 of 114 women, mean age $27 \pm 13$ years, with Turner syndrome confirmed by karyotype were found to have $\mathrm{Y}$ chromosome material on repeat genetic testing with PCR, 7 of whom did not have the Y chromosome material identified on original karyotyping [5]. Similar findings have been shown in Korean [13], Brazilian [10] and Hungarian [14] populations. Some studies have proposed that all patients with Turner syndrome and 45,X karyotypes carry a second chromosomal cell line, difficult to detect with standard testing [15]. In some cases, due to a low percentage of mosaicism, this may be due to an insufficient number of cells having been tested, or an insufficient number of tissues having been sampled. In our patient, despite the high percentage of Y chromosome material found in the peripheral sample (86\%), the duplicated $\mathrm{Y}$ cell line was mistakenly identified as a deleted X chromosome on the initial karyotype analysis, and reported as $46, \mathrm{X}, \operatorname{del}(\mathrm{X}) \mathrm{q} 13$. Standard karyotyping is not always the best way to identify cryptic Y chromosome material, and observation of any structural aberration of the sex chromosomes should therefore be followed with molecular cytogenetic investigation such as FISH and/or an arraybased diagnostic. Although microarray is not the gold standard under current clinical practice guidelines, given the discrepancy of the original karyotype in this case, mi- 
croarray was performed to delineate the breakpoints, and rule out any cryptic complexity.

It is important to accurately identify the precise Turner karyotype as it correlates with the severity of the Turner phenotype and specific sequelae [2]. For example, haploinsufficiency of genes on the long arm of the X chromosome is associated with gonadal dysgenesis, while patients with a deletion of the short arm usually have normal ovarian function [16]. Similarly, identifying a Y chromosome line in a patient with Turner syndrome is important due to the risk of gonadoblastoma, estimated to be about
7-10\% [5]. Gonadoblastoma is an in situ germ cell neoplasm, associated with an increased risk of developing invasive malignant germ cell tumors. These tumors are found in more than $30 \%$ of patients with XY gonadal dysgenesis and in $15-20 \%$ of those with mixed X/XY gonadal dysgenesis $[11,17]$. Conventional karyotype analysis may not reveal such findings, putting the patient at risk for malignant transformation if missed. PCR and FISH analysis may reveal information that is not discernable by conventional karyotyping and, as suggested by newer studies, should be used for enhanced screening of patients

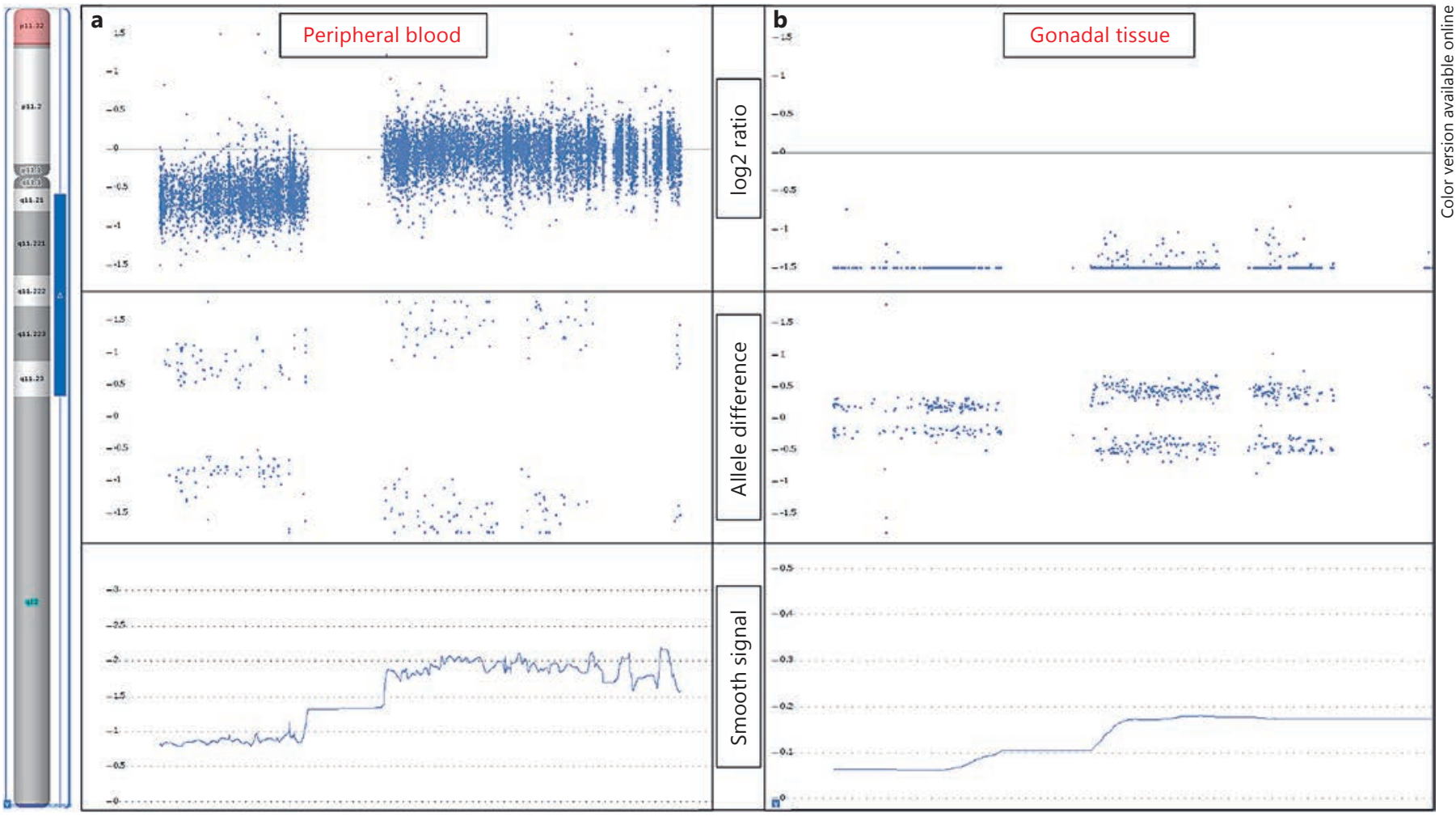

Fig. 2. Chromosome microarray analysis results. The region that is duplicated on the long arm of the $\mathrm{Y}$ chromosome is indicated by the blue bar in the ideogram on the left. a Chromosome microarray analysis performed on DNA extracted from peripheral blood showed an $86 \%$ prevalence of Y chromosome material with a duplication of the entire euchromatic region of the long arm (blue bar). The duplication is identified by the higher $\log 2$ ratio observed for probes in the long arm compared to those in the short arm as seen in the $\log 2$ ratio panel. b Chromosome microarray analysis performed on DNA extracted from gonadal tissue paraffin sections showed the same duplicated Y chromosome but at a $6.5 \%$ prevalence. The $\log 2$ ratios in $\mathbf{b}$ are distinctly diminished compared to $\mathbf{a}$, indicating a very low presence of $\mathrm{Y}$ chromosome material. However, the $\log 2$ ratio in the long arm remains noticeably increased over the short arm, representing the same structural Y chromosome as seen in peripheral blood but at a much lower prevalence. The allele difference panels indicate the genotype for each SNP probe. For normal copy number of 2 , there are only 3 possible $\mathrm{SNP}$ combinations, i.e., $\mathrm{AA}, \mathrm{AB}$, and $\mathrm{BB}$, which are plotted on the allele difference graph. When there is a single copy of a region (copy number of 1), the genotype options are either A or B and thus only two distinct tracks are visible on the allele difference graph. When the same region is duplicated, as in the long arm of the $\mathrm{Y}$ chromosome, there remain only 2 genotypes but they are represented as AA and $\mathrm{BB}$. The smooth signal copy number panels indicate the exact copy number of each probe. This panel is helpful in identifying mosaicism which is evident when the smooth signal for multiple consecutive probes lies between an integer, e.g., between 1 and 2. The level of mosaicism in peripheral blood is markedly higher compared to that observed in gonadal tissue. 
with Turner syndrome, particularly in those with marker chromosomes and even in those without signs of virilization $[4,11,10,18]$.

FISH for SRY alone, however, is not always adequate, and an array-based diagnostic should strongly be considered. Although SRY is important for other aspects of sexual differentiation, the SRY region of the Y chromosome has been found lacking in many patients with gonadoblastoma [19]. More recent literature suggests that FISH studies on patients with Turner syndrome should include probes that specifically target the SRY, TSPY, and DYZ3 gene regions to more adequately assess for the presence of cryptic Y chromosome material [7-9, 20]. In the pres-

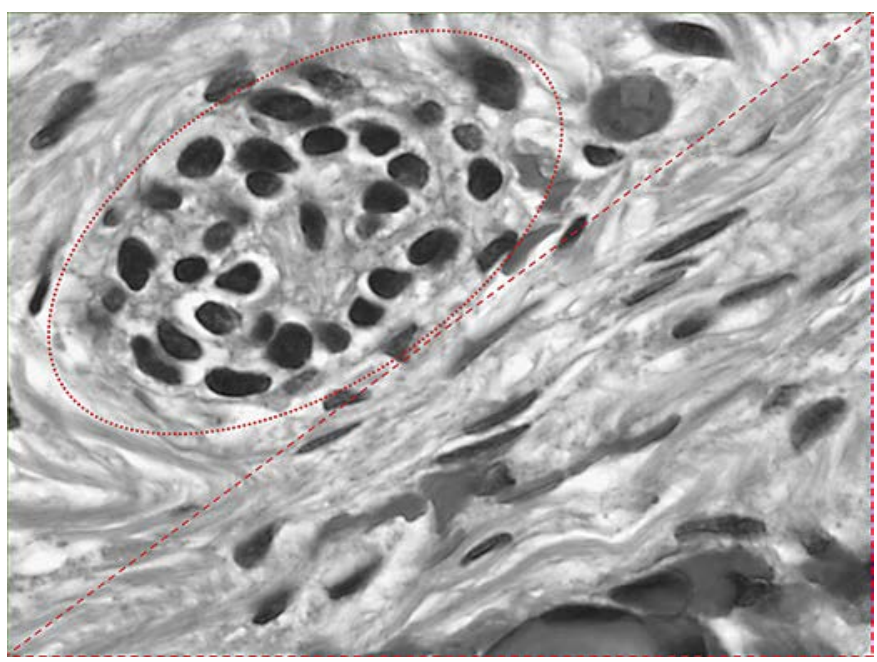

Fig. 3. Microscopic dissection of streak gonadal tissue. Tubal structures at the top left (red oval) with wavy ovarian stroma at the bottom right (red triangle). ent case, since the microarray analysis revealed that all regions of the $\mathrm{Y}$ chromosome were present in the $\operatorname{dup}(\mathrm{Y})$ (q11.21q11.23) cell line, the SRY probe was used as a marker for the presence of the aberrant $\mathrm{Y}$ chromosome.

Mizuno et al. [21] reported a case of mixed gonadal dysgenesis $(45, \mathrm{X} / 46, \mathrm{XY})$ in a phenotypic male whose right-sided streak gonad was negative for SRY despite SRY presence in the peripheral sample. Conversely, Bisat et al. [22] reported a case in which Y chromosome material was discovered in the gonad but was absent in the peripheral sample of a girl with Turner syndrome and virilization. Identifying $\mathrm{Y}$ chromosome material in the peripheral blood, therefore, does not necessarily predict its presence in gonadal tissue [23], and cannot be used as a proxy for gonadal prevalence. Our phenotypically female subject had an $86 \%$ prevalence of Y chromosome material in the peripheral blood and only a $6.5 \%$ prevalence in the gonadal tissue, verifying that mosaic distribution differs between tissues. Guedes et al. [23] reported a similar case of a woman with $45, \mathrm{X} / 46, \mathrm{X}, \mathrm{idic}(\mathrm{Yp})$ mosaicism who had a $97 \%$ Y chromosome prevalence in her peripheral lymphocytes, but only a $40 \%$ prevalence in the streak gonads.

Alvarez-Nava et al. [24] reported 3 subjects with the same karyotype, 45,X/46,X,+mar (Y) but 3 distinct phenotypic presentations. It was the gonosomal karyotype found in the majority of cells in the gonadal tissue that was correlated with the patients' phenotypic characteristics. Mazzanti et al. [11] reported 5 cases of gonadectomized Turner patients in which Y chromosome prevalence was lower in the gonadal tissue than in the blood. Identifying the prevalent gonosome karyotype is important, considering that it appears to influence phenotypic
Fig. 4. FISH using probes for the centromere of the X chromosome (green) and the SRY region on the short arm of the Y chromosome (red). SRY is present only in the tubal structures (left panel), while the ovarian stroma contains a single $\mathrm{X}$ chromosome with no SRY (right panel).
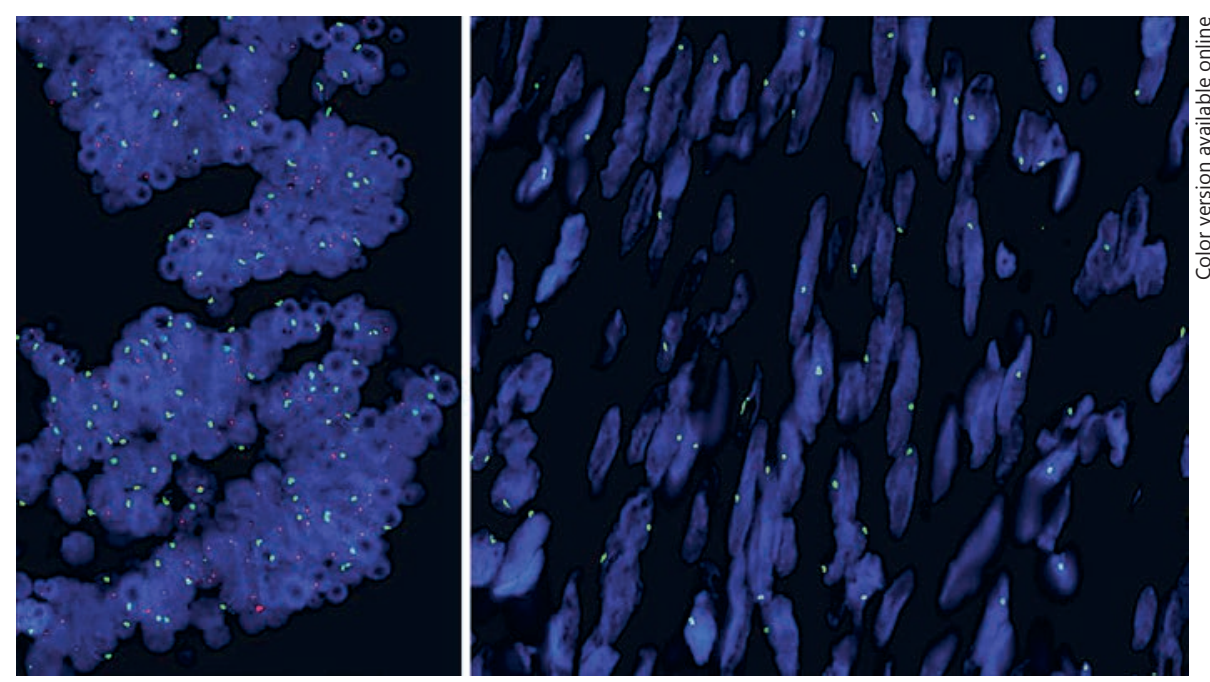

Y Prevalence and Tubal Structures in Turner Syndrome
Horm Res Paediatr DOI: $10.1159 / 000477240$ 
presentation $[23,25,26]$, and also likely impacts the risk of malignancy $[17,27]$. However, until the gonadal prevalence of Y chromosome material can be directly correlated with risk of malignancy, current management of such cases with prophylactic gonadectomy is most prudent.

Streak gonads are a type of dysgenetic gonad characterized primarily by ovarian stroma without sex cord or germ cell elements, though there may also be other cellular types present, such as rete structures [28]. In cases of Turner syndrome where there is evidence of Y chromosome material, streak gonads may also contain tubular structures indicative of potential testes [29] in addition to gonadoblastoma nests. Microscopic analysis of the streak gonads in our subject contained sheets of ovarian stroma along with areas showing tubule histology. The distribution of SRY in the gonadal sample correlated exclusively with the areas containing these tubal cells, while the areas with ovarian stroma showed the 45 , X karyotype. A similar distribution was reported by Salas-Cortés et al. [30] in patients with 46,XY pure gonadal dysgenesis. In the streak gonads of these patients, SRY was found in the nuclei of the rete and tubular cells. It has also been reported that there is a higher prevalence of $Y$ chromosome material in gonadoblastoma cells as compared with the surrounding nontumor cells [31], perhaps suggesting an association between Y chromosomal distribution or concentration and malignancy risk. It is also interesting that in our sub- ject, evidence of tubal formation was seen in the streak gonad despite only a $6.5 \%$ prevalence of $\mathrm{Y}$ chromosome material. As we cannot currently use Y prevalence and distribution in the gonad, or the mere presence of tubal structures, to predict specific risk of developing gonadoblastoma and malignant transformation, we felt that gonadectomy in this patient was certainly justified, and the most prudent course of management. Whether this pattern of expression confers risk of malignancy is unclear and further investigation in this area is warranted.

\section{Acknowledgement}

This paper was supported by NIH/NIDDK T32DK065522 (to T.G.B. and S.E.O.).

\section{Statement of Ethics}

As per the Columbia University Institutional Review Board, case reports of a single patient that do not contain unique identifiers do not require Institutional Review Board approval. As per the privacy office, this case has been de-identified and contains no unique identifiers.

\section{Disclosure Statement}

None of the authors have any conflicts of interest to declare.

\section{References}

1 Stockholm K, Juul S, Juel K, Naeraa RW, Gravholt $\mathrm{CH}$ : Prevalence, incidence, diagnostic delay, and mortality in Turner syndrome. J Clin Endocrinol Metab 2006;91:3897-3902.

-2 Bispo A, Dos Santos LO, Burégio-Frota P, Galdino MB, Duarte AR, Leal GF, Araújo J, Gomes B, Soares-Ventura EM, Muniz MT, Santos N: Effect of chromosome constitution variations on the expression of Turner phenotype. Genet Mol Res 2013;12:4243-4250.

-3 Saenger P, Wikland KA, Conway GS: Recommendations for the diagnosis and management of Turner syndrome. J Clin Endocrinol Metab 2001;86:3061-3069.

-4 Cortés-Gutiérrez EI, Herrera-Bartolo R, Dávila-Rodríguez MI, Palacios-Saucedo GC, Vargas-Villarreal J, Romero-Villarreal JB: Molecular detection of cryptic Y-chromosomal material in patients with Turner syndrome. Oncol Rep 2012;28:1205-1210.
5 Gravholt C, Fedder J, Naeraa RW, Müller J: Occurrence of gonadoblastoma in females with Turner syndrome and Y chromosome material: a population study. J Clin Endocrinol Metab 2000;85:3199-3202.

6 Zinn A, Page DC: Turner syndrome and the Y chromosome; in Hibi I, Takano K (eds): Basic and Clinical Approach to Turner Syndrome. Amsterdam, Elsevier, 1993, pp 49-56.

7 Ackermann A, Bamba V: Current controversies in turner syndrome: genetic testing, assisted reproduction, and cardiovascular risks. J Clin Transl Endocrinol 2014;1:61-65.

-8 Kersemaekers A, Honecker F, Stoop H, Cools M, Molier M, Wolffenbuttel K, Bokemeyer C, Li Y, Lau YF, Oosterhuis JW, Looijenga LH: Identification of germ cells at risk for neoplastic transformation in gonadoblastoma: an immunohistochemical study for OCT3/4 and TSPY. Hum Pathol 2005;36:512-521.
-9 Hertel JD, Huettner P, Dehner L, Pfeifer J: The chromosome $Y$-linked testis specific protein locus TSPY1 is characteristically present in gonadoblastoma. Hum Pathol 2010;41: 1544-1549.

10 Bianco B, Lipay MV, Melaragno MI, Guedes $A D$, Verreschi IT: Detection of hidden Y mosaicism in Turner's syndrome: importance in the prevention of gonadoblastoma. J Pediatr Endocrinol Metab 2006;19:1113-1117.

11 Mazzanti L, Cicognani A, Baldazzi L, Bergamaschi R, Scarano E, Strocchi S, Nicoletti A, Mencarelli F, Pittalis M, Forabosco A, Cacciari E: Gonadoblastoma in Turner syndrome and Y chromosome derived material. Am J Med Genet A 2005;135:150-154.

12 Bispo A, Buregio-Frota O, Oliveira dose Santos L, Leal GF, Duarte AR, Araujo J, Cavalcante da Silva V, Muniz MT, Liehr T, Santos $\mathrm{N}$ : Y chromosome in Turner syndrome: detection of hidden mosaicism and the report of a rare $\mathrm{X} ; \mathrm{Y}$ translocation case. Reprod Fertil Dev 2014;26:1176-1182. 
$13 \mathrm{Kim} \mathrm{H}$, Shin JH, Jung WY, Lee JN: Identification of $\mathrm{Y}$ chromosome by molecular analysis in patients with Turner syndrome. Korean J Lab Med 2006;26:131-136.

14 Sallai A, Solyom J, Dobos M, Szabó J, Halász Z, Ságodi L, Niederland T, Kozári A, Bertalan R, Ugocsai P, Fekete G: Y chromosome markers in Turner syndrome: screening of $130 \mathrm{pa}-$ tients. J Endocrinol Invest 2010;33:222-227.

15 Held K, Kerber S, Kaminsky E: Mosaicism in 45 ,X Turner syndrome: does survival in early pregnancy depend on the presence of two sex chromosomes. Hum Genet 1992;88:288-294.

16 Davison R, Fox M, Conway GS: Mapping of the POF1 locus and identification of putative genes for premature ovarian failure. Mol Hum Reprod 2000;6:314-318.

-17 Verp M, Simpson JL: Abnormal sexual differentiation and neoplasia. Cancer Genet Cytogenet 1987;25:191-218.

18 Chu C, Connor JM, Donaldson MD, Kelnar CJ, Smail PJ, Greene SA: Detection of Y mosaicism in patients with Turner's syndrome. J Med Genet 1995;32:578-580.

19 Kido T, Lau YF: Roles of the Y chromosome genes in human cancers. Asian J Androl 2015; $17: 373-380$
20 de Marqui A, da Silva-Grecco RL, Balarin MA: Prevalence of Y-chromosome sequences and gonadoblastoma in Turner syndrome. Rev Paul Pediatr 2016;34:114-121.

21 Mizuno K, Kojima Y, Tozawa K, Sasaki S, Hayashi Y, Kohri K: Molecular evaluation of the SRY gene for gonads of patients with mixed gonadal dysgenesis. Int J Urol 2005;12: 673-676.

22 Bisat T, May K, Litwer S, Broecker B: Y chromosome mosaicism in the gonads, but not in the blood, of a girl with the Turner phenotype and virilized external genitalia. Clin Genet 1993;44:142-145.

23 Guedes A, Bianco B, Lipay MV, Brunoni D, de Lourdes Chauffaille M, Verreschi IT, Determination of the sexual phenotype in a child with 45,X/46,X,Idic(Yp) mosaicism: importance of the relative proportion of the 45,X line in gonadal tissue. Am J Med Genet A 2006;140A:1871-1875.

24 Alvarez-Nava F, Soto M, Martínez MC, Prieto $\mathrm{M}$, Alvarez Z: FISH and PCR analyses in three patients with $45, \mathrm{X} / 46, \mathrm{X}, \operatorname{idic}(\mathrm{Y})$ karyotype: clinical and pathologic spectrum. Ann Genet 2003;46:443-448.
25 Kelly T, Franko JB, Rogol A, Golden WL: Discordant phenotypes and 45,X/46,X,idic(Y). J Med Genet 1998;35:862-864.

-26 Telvi L, Lebbar A, Del Pino O, Barbet JP, Chaussain JL: 45,X/46,XY mosaicism: report of 27 cases. Pediatrics 1999;104:304-308.

27 Scully R: Gonadoblastoma. A review of 74 cases. Cancer 1970;25:1340-1356.

28 Boyd TK: Disorders of sexual differentiation. Surg Pathol Clin 2010;3:553-601.

29 Vilain E, Jaubert F, Fellous M, McElreavey K: Pathology of 46,XY pure gonadal dysgenesis: absence of testis differentiation associated with mutations in the testis-determining factor. Differentiation 1993;52: 151-159.

30 Salas-Cortés L, Jaubert F, Nihoul-Feketé C, Brauner R, Rosemblatt M, Fellous M: SRY protein is expressed in ovotestis and streak gonads from human sex-reversal. Cytogenet Cell Genet 2000;91:212-216.

31 Iezzoni J, Von Kap-Herr C, Golden WL, Gaffey MJ: Gonadoblastomas in 45,X/46,XY mosaicism: analysis of $\mathrm{Y}$ chromosome distribution by fluorescence in situ hybridization. Am J Clin Pathol 1997;108:197-201. 